2015-01

\title{
Buckling analysis of cold-formed steel channel-section beams at elevated temperatures
}

\author{
Cheng, Shanshan
}

http://hdl.handle.net/10026.1/10963

\begin{abstract}
10.1016/j.jcsr.2014.10.004
Journal of Constructional Steel Research

Elsevier BV
\end{abstract}

All content in PEARL is protected by copyright law. Author manuscripts are made available in accordance with publisher policies. Please cite only the published version using the details provided on the item record or document. In the absence of an open licence (e.g. Creative Commons), permissions for further reuse of content should be sought from the publisher or author. 
The paper has been accepted to publish on:

Journal of Constructional Steel Research, Volume 104, Jan 2015, 74-80.

Buckling analysis of cold-formed steel channel-section beams at elevated temperatures

Shanshan Cheng, Long-yuan Li, Boksun Kim

School of Marine Science and Engineering, University of Plymouth, Plymouth, UK

Fax: +44 (0)1752586101; email address: shanshan.cheng@ @lymouth.ac.uk

\begin{abstract}
This paper presents a numerical investigation on the buckling behaviour of plasterboard protected CFS channel-section beams subjected to uniformly distributed loads when exposed to fire on its one side. The work involves three phases, namely heat transfer analysis, pre-buckling analysis and buckling analysis. The heat transfer analysis is accomplished using two-dimensional finite element analysis methods, from which the temperature fields of the channel-section beams are obtained. The pre-buckling analysis is completed using the Bernoulli bending theory of beams with considering the effects of temperature on strain and mechanical properties. The buckling analysis is performed using combined finite strip analysis and classical Fourier series solutions, in which the mechanical properties are considered to be temperature dependent. The results show that there are significant temperature variations in web, fire exposed flange and lip. Also, it is found that the buckling behaviour of the beam with temperature variation in its section is quite different from that of the beam with a constant uniform temperature in its section.
\end{abstract}

Keywords: Thin-walled; cold-formed steel; buckling; fire; temperature; channel.

\title{
1. Introduction
}

Thin-walled, cold-formed steel (CFS) members are traditionally used as purlins, the intermediate members in a roof system to support the corrugated roof or wall sheeting and transmit the force to the main structural frame. In recent years CFS has been also increasingly used as load-bearing components in low- and mid-rise buildings due to its advantages of high strength-to-weight ratio, ease of fabrication, and the flexibility of sectional profiles. However, the features such as thin thickness, open cross-section and great flexural rigidity difference about two cross-sectional axes, lead the buckling failure to be the main failure mode of CFS members [1]. When it is exposed to a fire, the rapid temperature rise in a CFS member makes the buckling behaviour even worse because of the reduced mechanical properties at elevated temperatures [2]. If the temperature distribution in a member is uniform, the buckling behaviour of the member can be analysed based on uniformly reduced material properties. However, if the temperature distribution in a member is not uniform, which usually happens in internal walls and/or floor panels when CFS members are exposed to fire on one side, the temperature-dependent material properties vary within the member. This makes the analysis of structures much complicated, the problem of which is not fully addressed in the existing analysis of CFS members.

The buckling resistance of CFS columns at elevated temperatures has been investigated by many researchers, for example [3-5]. However, limited studies could be found on the buckling behaviour of CFS beams in fire. The lateral-torsional buckling behaviour of CFS beams under uniform temperatures has been studied by Kankanamge and Mahendran [6] based on their experimentally obtained mechanical properties [7]. The comparison of their 
results with the design code recommended in EN1993-1-2 [8] showed that the design method presented in EN1993-1-2 is over-conservative for most members except that the members are very slender. It was also recognized that the moment capacity data were scattered in the intermediate slenderness range and therefore separate buckling curves are needed for different elevated temperatures in order to give accurate design prediction. Furthermore, the temperature limit of $350{ }^{\circ} \mathrm{C}$ for CFS recommended in EN1993-1-2 was found over conservative for CFS beams in fire [6,9]. Recently, Laím et al. have carried out an experimental study on the buckling resistance of CFS beams in fire [10]. Channel section and compounded lipped I-, R- and 2R-section beams were tested under various boundary conditions. It was found that the critical temperature of all simply supported beams went up to about $700{ }^{\circ} \mathrm{C}$. Therefore a demand of an accurate design guideline has been raised to extend the use of CFS.

Direct Strength Method (DSM) [11] has been adopted as an alternative design method to the Effective Width Method (EWM) due to the advantages of no need for tedious calculation of effective width. Since the buckling resistance could be directly determined by using DSM based on the elastic buckling loads and the squash load, an accurate calculation of member elastic buckling load is essential. The eigenvalue analysis software CUFSM [12] based on the Finite Strip Method (FSM) has been widely adopted typically to get the elastic buckling loads. However, since CUFSM was developed under ambient temperature, the effect of thermal expansion on the stress distribution and the shift of neutral axis under non-uniform temperatures are not taken into account in the code. The present study is therefore to further explore the application of FSM to the buckling analysis of CFS members at elevated temperatures by considering non-uniform temperature distribution in the members.

\section{Heat transfer}

CFS sections utilised in buildings are usually protected by plasterboards or other fire resistant materials in order to increase their fire resistance. Thus, when they are exposed to a fire environment the temperature in CFS members will be much less than the fire temperature. Depending on how the member is protected, the temperature in a CFS member may be treated as time-dependent or both time- and position-dependent. The former means that the temperature is uniformly distributed within the member although it may vary with time, while the latter means that the temperature within the member varies with both time and position. Analytical approaches have been developed for calculating the uniform temperature in fire protected members using the concept of energy conservation [2]. For members with nonuniform temperature distribution numerical methods of heat transfer are normally used, in which the protected member and protection material are treated as a system for which the heat transfer analysis is conducted.

Consider a channel-section beam that is protected by plasterboard on its one side, as is shown in Fig. 1. When a fire occurs underneath the plasterboard heat will transfer from the fire to the beam through the plasterboard. The actual temperature distribution in the beam can be calculated using the theory of heat transfer as follows,

$\rho c \frac{\partial T}{\partial t}=\nabla \cdot(\lambda \nabla T)$

where $\rho$ is the density, $c$ is the specific heat, $T$ is the temperature, $t$ is the time, $\lambda$ is the thermal conductivity. For the case where the fire is uniform along the beam length, the heat transfer can be treated as a two-dimensional plane problem within the cross-section of the beam. The boundary conditions of Eq. (1) can be expressed as follows, 
On the fire exposed surface:

$\lambda \frac{\partial T}{\partial n}=\alpha_{g}\left(T_{g}-T\right)+\varepsilon_{g} \sigma\left[\left(T_{g}+273\right)^{4}-(T+273)^{4}\right]$

On the ambient exposed surface:

$\lambda \frac{\partial T}{\partial n}=\alpha_{a}\left(T_{a}-T\right)+\varepsilon_{a} \sigma\left[\left(T_{a}+273\right)^{4}-(T+273)^{4}\right]$

On the symmetric plane:

$\lambda \frac{\partial T}{\partial n}=0$

where $n$ is the surface normal, $\alpha_{g}=25 \mathrm{~W} / \mathrm{m}^{2} \mathrm{~K}$ is the coefficient of heat transfer by convection on the fire exposed surface, $\alpha_{a}=9 \mathrm{~W} / \mathrm{m}^{2} \mathrm{~K}$ is the coefficient of heat transfer by convection on the ambient exposed surface, $T_{g}$ is the fire temperature in the vicinity of the fire exposed surface, $T_{a}$ is the air temperature in the vicinity of the ambient exposed surface, $\varepsilon_{g}=0.7$ is the surface emissivity on the fire exposed surface, $\varepsilon_{a}=1$ is the surface emissivity on the ambient exposed surface, and $\sigma=5.67 \times 10^{-8} \mathrm{~W} / \mathrm{m}^{2} \mathrm{~K}^{4}$ is the Stephan Boltzmann constant.

For the present problem Eq. (1) is applied to the fire exposed surface of the plasterboard, Eq. (4) is applied to the two vertical sides of the plasterboard because of the periodically symmetrical boundary condition, and Eq. (3) is applied to all exposed surfaces of the channel section. Solving Eq. (1) with the boundary conditions defined by Eq. (2)-(4) using finite element methods the temperature distribution in the channel section can be obtained. The material properties used in the heat transfer analysis are given in [13] for the plasterboard and [8] for the CFS. Fig. 2 plots the temperature distributions in the channel section at three different times, in which the fire temperature is defined using a standard fire curve, i.e. $T_{g}=$ $T_{a}+345 \log (8 t / 60+1)$ and the air temperature is defined as a constant, i.e. $T_{a}=20{ }^{\circ} \mathrm{C}$. As is to be expected, the temperature in the channel section is found to be higher at a point that is closer to the fire exposed surface. It can be seen from Fig. 2 that the variation of temperature in the fire exposed flange, fire exposed lip and web is quite significant, indicating that the temperature is not uniformly distributed in these elements. Compared to the temperature in the fire exposed elements, the temperature in the fire unexposed flange and lip remains low even after an hour of the fire exposure. Note that the highest temperature in the channel section is much lower than the fire temperature because of the use of $12.5 \mathrm{~mm}$ thick plasterboard protection. For example, after an hour fire exposure, the highest temperature in the two channel sections is $250^{\circ} \mathrm{C}$, while the fire temperature at the same time is about 945 ${ }^{\circ} \mathrm{C}$.

\section{Pre-buckling analysis}

The channel section is not symmetric about the principal axis parallel to its web line. Its shear centre is also not at the centroid. However, when they are used in buildings to support the loading on the floor or ceiling, several channel-section beams are usually used together (see Fig. 1). In this case the transverse loading on the channel-section beam can be assumed to act at the shear centre of the section.

If the channel section has a uniformly distributed temperature then the mechanical properties of the section are also symmetric about its geometrically symmetric axis. However, if the temperature is not uniform in the cross-section then the mechanical properties will no longer 
be symmetric about its geometrically symmetric axis. In this case the bending of the beam has to be treated as an asymmetric bending case.

Let $o$ be the centroid of the channel-section, $x$ be the longitudinal axis, $y$ and $z$ be the two geometrically principal axes of the cross-section, respectively. By using Bernoulli beam's assumption, the axial strain at any coordinate point of the cross-section can be expressed as the sum of a membrane strain and two bending strains as follows,

$\varepsilon(y, z)=\varepsilon_{o}+y \kappa_{x y}+z \kappa_{x z}$

where $\varepsilon_{o}$ is the membrane strain, $\kappa_{x y}$ and $\kappa_{x z}$ are the curvatures of the beam in the $x y$ - and $x z$ planes, respectively. On the other hand, the total axial strain can also be decomposed in terms of the components generated by individual actions,

$\varepsilon(y, z)=\frac{\sigma_{s}}{E(T)}+\varepsilon_{t h}(T)$

where $\sigma_{s}$ is the axial stress, $E$ is the temperature-dependent Young's modulus, and $\varepsilon_{t h}$ is the thermal strain. Solve $\sigma_{s}$ from Eqs. (5) and (6), yielding,

$\sigma_{s}=E\left(\varepsilon_{o}+y \kappa_{x y}+z \kappa_{x z}-\varepsilon_{t h}\right)$

The resultant force and moments on the cross-section requires the following equilibrium equations,

$$
\begin{aligned}
& N_{x}=\int_{A} \sigma d A=\int_{A} E\left(\varepsilon_{o}+y \kappa_{x y}+z \kappa_{x z}-\varepsilon_{t h}\right) d A \\
& =\varepsilon_{o} \int_{A} E d A+\kappa_{x y} \int_{A} y E d A+\kappa_{x z} \int_{A} z E d A-\int_{A} E \varepsilon_{t h} d A=0 \\
& M_{z}=\int_{A} y \sigma d A=\int_{A} y E\left(\varepsilon_{o}+y \kappa_{x y}+z \kappa_{x z}-\varepsilon_{t h}\right) d A \\
& =\varepsilon_{o} \int_{A} y E d A+\kappa_{x y} \int_{A} y^{2} E d A+\kappa_{x z} \int_{A} y z E d A-\int_{A} y E \varepsilon_{t h} d A \\
& M_{y}=\int_{A} z \sigma d A=\int_{A} z E\left(\varepsilon_{o}+y \kappa_{x y}+z \kappa_{x z}-\varepsilon_{t h}\right) d A \\
& \quad=\varepsilon_{o} \int_{A} z E d A+\kappa_{x y} \int_{A} y z E d A+\kappa_{x z} \int_{A} z^{2} E d A-\int_{A} z E \varepsilon_{t h} d A=0
\end{aligned}
$$

where $N_{x}$ is the axial membrane force, $M_{y}$ and $M_{z}$ are the bending moments about $y$ - and $z$ axes, respectively. For a simply supported channel-section beam $M_{z}=q x(l-x) / 2$ where $q$ is the uniform load and $l$ is the beam length. Note that if the beam is fully restrained in its lateral direction then $\kappa_{x z}=0$ instead of using $M_{y}=0$. The integrations involved in Eqs. (8)-(10) require the Young's modulus, which decreases with increased temperature. Fig. 3 graphically shows the variations of the Young's modulus and yield strength of CFS with temperature, which are obtained from experiments [7].

Eqs. (8)-(10) can be used to determine the membrane strain $\left(\varepsilon_{o}\right)$ and bending curvatures $\left(\kappa_{x y}\right.$ and $\kappa_{x z}$ ) of the beam, which are then substituted into Eq. (7) to obtain the axial stress $\sigma_{s}$. Note that if the temperature is uniformly distributed within the cross section, the stress distribution generated by the moment $M_{z}$ will follow the conventional distribution of bending stress. However, if a fire occurs only on one side of the member, for instance, as shown in Fig. 1, the temperature will be non-uniform in the cross section and so do the material properties. In this case the axial stress distribution across the section has to be determined using Eqs. (7)-(10) based on the actual temperature distribution and the temperature-dependent Young's modulus. 
The axial stress distributions on the middle section of the two channel-section beams under non-uniform temperature distributions are plotted in Fig. 4, in which the temperatures are obtained from the heat transfer analysis described in Section 2 and a yield uniformly distributed load is used (that is $q l^{2} / 8=M_{y, T_{o}}$ where $M_{y, T_{o}}=2 \sigma_{y o} I_{z} / d$ is the yield moment of the beam, $\sigma_{y o}$ is the yield stress at ambient temperature and $I_{z}$ is the second moment of crosssectional area of the beam about z-axis). The first- and second-row in Fig. 4 are for the small and large channel sections, respectively. The compressive stress is taken as positive and the tensile stress is as negative. It is revealed in Fig. 4 that the non-uniform temperature distribution influences the stress distribution within the cross-section remarkably. The largest compressive stress is found to occur at the junction between web and fire unexposed flange and it increases with the rise of temperature. The largest tensile stress is found to be either at the end of the fire exposed lip or in the web depending on the fire temperature and sectional dimensions, which also increases with the rise of temperature. The tension region in web is clearly increased as temperature rises, indicating the shift of the neutral axis towards to the compressed flange where the temperature is low. This is due to the variation of elastic modulus within the cross-section caused by the non-uniform temperature. The figure also shows that the stress distribution varies almost linearly along the flanges, lips and most part of the web, except for some part of the web near the fire exposed flange. This is mainly because the nonlinear temperature distribution introduces a nonlinear thermal expansion, which generates a local bending in order that the cross-section remains in plane. The local bending increases the tensile stress in the web with a lower temperature, and the influence becomes more remarkable under a higher nonlinear temperature distribution, as shown in Fig. 4(c) and 4(f).

\section{Buckling analysis}

Buckling analysis can be completed in a variety of ways. The commonly used methods include the finite element analysis, finite strip analysis, classical Fourier series solutions, and generalized beam theory method [12]. For CFS members subjected to pure compression and/or pure bending, the finite strip analysis is the most effective method [14]. However, if the CFS members are subjected to transverse loading, one has to combine the finite strip analysis and classical Fourier series solutions $[15,16]$ due to the variation of pre-buckling stresses along the longitudinal axis.

To apply the combined finite strip analysis and classical Fourier series solutions to CFS members subjected to transverse loading at elevated temperatures, one has to modify the existing finite strip analysis by taking into account the temperature effect on the Young's modulus. Using the pre-buckling stress given by Eq. (7) and the Young's modulus defined in Fig. 3, similar matrix equations to those given in $[15,16]$ but with different matrix coefficients have been derived by Cheng [17], from which the critical buckling load is determined. The mathematical details for the modified finite strip analysis can be found in [17] and thus will not be provided further here.

Fig. 5 shows the dimensionless critical moments $\left(M_{c r}=q l^{2} / 8\right.$ is the critical bending moment at the middle of the beam) of the two channel-section beams subjected to a uniformly distributed transverse load. The different curves shown in the figure are defined by the maximum temperatures occurring in the sections. For example, the curve with $T=300{ }^{\circ} \mathrm{C}$ represents the buckling curve of the beam when the maximum temperature in any place in the beam reaches $300{ }^{\circ} \mathrm{C}$. It is observed from Fig. 5 that the critical moment decreases generally 
with the beam length. For the small section beam $(d=200 \mathrm{~mm})$ there are three regions, which are defined in terms of the beam length, representing the local, distortional and lateraltorsional buckling; while for the large section beam $(d=300 \mathrm{~mm})$ only two regions are observed, representing the local and lateral-torsional buckling. In the local buckling region the critical moment in most curves is found to decrease with increased beam length until it reaches a minimum value after which it keeps unchanged. In the distortional buckling region the critical moment also decreases with increased beam length until the buckling mode changes to lateral-torsional buckling mode in which case the decrease becomes fast. The reason of reduction in the critical moments of local and distortional buckling is due to the parabolic distribution of pre-buckling stress along the beam length, which has been explained previously by $\mathrm{Chu}$ et al. [16]. Note that the two buckling curves corresponding to temperatures $500{ }^{\circ} \mathrm{C}$ and $600{ }^{\circ} \mathrm{C}$ are slightly different from others. This is mainly due to the shift of the neutral axis of the cross-section under non-uniform temperature distributions. As a result of this, the local buckling moment near the lateral-torsional buckling region increases slightly with the increased beam length. In general the critical moment is lower if the temperature is higher with the exception in the distortional buckling region where the critical moments are in the opposite order. This is probably due to the combined influence of the neutral axis shift as mentioned above and the interaction between local and distortional buckling. It is interesting to notice that for the lateral torsional buckling although the high temperature $T$ influences the critical buckling moment, the effect is almost negligible. This is probably due to the low temperature in the compression zone since the fire exposed surface is on the tension side of the beam and although the temperature increases in the tension zone the temperature in the compressed flange remains low, as is demonstrated in Fig. 2.

In order to examine whether the material yield has occurred when the beam buckles, Fig. 6 re-plots the critical moment of Fig. 5 by using the relative critical moment $M_{c r} / M_{y, T}$ where $M_{y, T}=M_{y, T 0^{*}} \eta$ is the yield moment of the beam and $\eta$ is the reduction factor of the yield moment at temperature $T$ [17], which is defined as $\eta=\min \left(\sigma_{y, T} / \sigma_{s, T}\right)$ where $\sigma_{y, T}$ and $\sigma_{s, T}$ are the yield stress and pre-buckling stress at temperature $T$, respectively. Since the ratio of $\sigma_{y, T} / \sigma_{s, T}$ varies with position, a minimum value is taken for $\eta$. It can be seen from the figure that, due to the value of $M_{y, T}$ decreases with increased temperature, the relative critical moment increases steadily with increased temperature. This indicates that the slenderness of the channel-section beam will decrease with the increase of temperature, particularly for $T>$ $400{ }^{\circ} \mathrm{C}$. This finding applies to both the small and large channel section beams.

To examine the difference in buckling behaviour between beams with constant [18] and varying temperature distributions in their cross-sections, Fig. 7 shows the dimensionless critical moments of the two channel-section beams subjected to a uniformly distributed transverse load, with a constant temperature $T$ in its cross-section, in which $M_{c r}$ is calculated using a uniform temperature distribution in its section. Comparing the critical buckling curves shown in Fig. 7 and those shown in Fig. 5, one can clearly see that for beams with a constant temperature distribution, the higher the temperature in the beam, the lower the critical moment of the beam, although the variation of the critical moment to the temperature is greater in the local buckling region than in the lateral-torsional buckling region. Another significant difference between Fig. 5 and Fig. 7 is the critical moment of lateral torsional buckling. In the former all curves almost lie together, while in the latter they are not.

Fig. 8 shows the relative critical moment $M_{c r} / M_{y, T}$ of the two channel-section beams with a constant temperature distribution in their cross-sections. Note that the relative critical moment curves for $T<300{ }^{\circ} \mathrm{C}$ are not corresponding to the order of the temperatures 
although the difference between them is rather small. This is mainly due to the different reduction rates of Young's modulus and yield strength of the CFS material in the temperature regions less and greater than $300{ }^{\circ} \mathrm{C}$ (see Fig. 3). The apparent difference between Fig. 6 and Fig. 8 indicates that the temperature variation in the section could significantly change the slenderness and thus the fire performance of the beam. Therefore the use of correct temperature distribution is very important in order to predict accurate buckling loads/moments and to fully understand the buckling behaviour of CFS beams at elevated temperatures.

\section{Conclusions}

This paper has presented a numerical investigation on the buckling behaviour of plasterboard protected CFS channel-section beams subjected to uniformly distributed loads when exposed to fire. The work involves three phases, namely heat transfer analysis, pre-buckling analysis and buckling analysis. The heat transfer analysis has been accomplished using twodimensional finite element analysis methods, from which the temperature fields of the channel-section beams are obtained. The pre-buckling analysis has been completed by using the Bernoulli bending theory of beams with considering both effects of temperature on strain and mechanical properties. The buckling analysis has been performed by using combined finite strip analysis and classical Fourier series solutions, in which the mechanical properties are considered to be temperature dependent. From the results obtained the following conclusions can be drawn:

- Significant temperature variation is found along the web, fire exposed flange and lip of the plasterboard protected CFS channel-section beam. Although the temperature in the fire exposed flange increases promptly with the exposed time the temperature in the fire unexposed flange remains low.

- The temperature variation within the section has significant influence on the distribution of pre-buckling stress of the channel section beam subjected to uniform transverse load. High temperature zone has low pre-buckling stresses and low temperature zone has high pre-buckling stresses, which leads to a shift of neutral axis towards to the low temperature zone.

- For the case where the fire is on the tension side of the beam, the fire will reduce the size of the compression zone but increase the magnitude of the maximum compressive stress on the fire unexposed flange. The former has a positive effect on the lateral-torsional buckling but almost no effect on the local buckling of the beam, whereas the latter has a negative effect on both lateral-torsional and local buckling of the beam.

- The temperature variation within the section has a significant influence on the calculation of slenderness of the beam. Thus the fire design formulae developed for beams of uniform temperatures may not be applied to the beams of non-uniform temperatures.

Acknowledgement - The first author wishes to acknowledge the financial support received from the Chinese Scholarship Council for her PhD study being carried out at Plymouth University.

\section{References}


[1] Li LY, Chu XT. Cold-formed steel sections (chapter 11). In: L Martin and JA Purkiss: "Structural Design of Steelwork to EN1993 and EN1994", Elsevier, Oxford, 2008.

[2] Purkiss JA, Li LY. Fire Safety Engineering Design of Structures ( $3^{\text {rd }}$ Edition). CRC Press, Oxford, 2013.

[3] Chen W, Ye J, Bai Y, Zhao XL. Improved fire resistant performance of load bearing coldformed steel interior and exterior wall systems. Thin-Walled Structures 2013; 73(0): 145-157. [4] Gunalan S. Mahendran M. Development of improved fire design rules for cold-formed steel wall systems. Journal of Constructional Steel Research 2013; 88: 339-362.

[5] Shahbazian A, Wang YC. Calculating the global buckling resistance of thin-walled steel members with uniform and non-uniform elevated temperatures under axial compression. Thin-Walled Structures 2011; 49(11): 1415-1428.

[6] Kankanamge DN, Mahendran M. Behaviour and design of cold-formed steel beams subject to lateral-torsional buckling at elevated temperatures. Thin-Walled Structures 2012; 61: 213-228.

[7] Kankanamge DN, Mahendran M. Mechanical properties of cold-formed steels at elevated temperatures. Thin-Walled Structures 2011; 49 (1): 26-44.

[8] EN 1993-1-2. Eurocode 3: Design of Steel Structures. Part 1-2: General Rules-Structural Fire Design. BSI, 2005.

[9] Lu W, Maekelaeinen P, Outinen J. Numerical simulation of catenary action in coldformed steel sheeting in fire. Journal of Structural Mechanics 2007; 40(3): 28-37.

[10] Laím L, Rodrigues JPC, da Silva LS. Experimental analysis on cold-formed steel beams subjected to fire. Thin-Walled Structures 2014; 74: 104-117.

[11] Schafer BW. Review: The direct strength method of cold-formed steel member design. Journal of Constructional Steel Research 2008; 64(7/8): 766-778.

[12] Papangelis JP, Hancock GJ. Computer analysis of thin-walled structural members. Computers \& Structures 1995; 56 (1): 157-176.

[13] Kontogeorgos D, Ghazi WK, Hugi E, Founti M. Heat and moisture transfer through a steel stud gypsum board assembly exposed to fire. Construction and Building Materials 2012; 26:746-54.

[14] Schafer BW. Cold-formed steel behaviour and design: Analytical and numerical modelling of elements and members with longitudinal stiffeners. PhD Thesis. Cornell University, 1997.

[15] Chu XT. Failure Analysis of Cold-formed Steel Sections. PhD Thesis, Aston University, 2004.

[16] Chu XT, Ye ZM, Kettle R, Li LY. Buckling behaviour of cold-formed channel sections under uniformly distributed loads. Thin-Walled Structures 2005; 43(4): 531-542.

[17] Cheng SS. Fire Performance of Cold-formed Steel Sections. PhD Thesis. University of Plymouth, 2014.

[18] Shahbazian A, Wang YC. Application of the direct strength method to local buckling resistance of thin-walled steel members with non-uniform elevated temperatures under axial compression. Thin-Walled Structures 2011; 49(12): 1573-1583. 


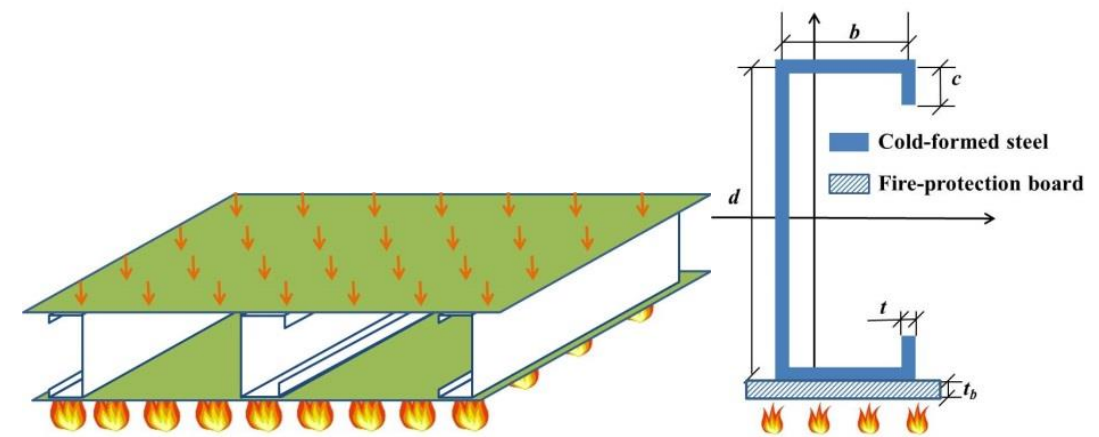

(a)

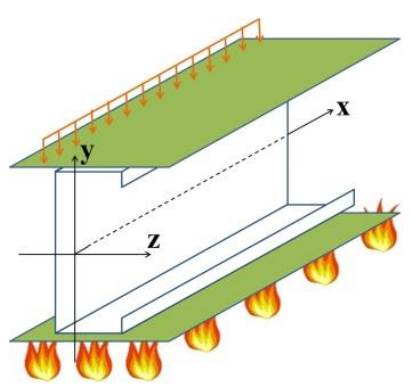

(c)

Fig.1 CFS channel-section beams subjected to transverse loading in fire. (a) Beam-sheet in system. (b) Boundary conditions used in heat transfer analysis. (c) Model used in prebuckling stress analysis.

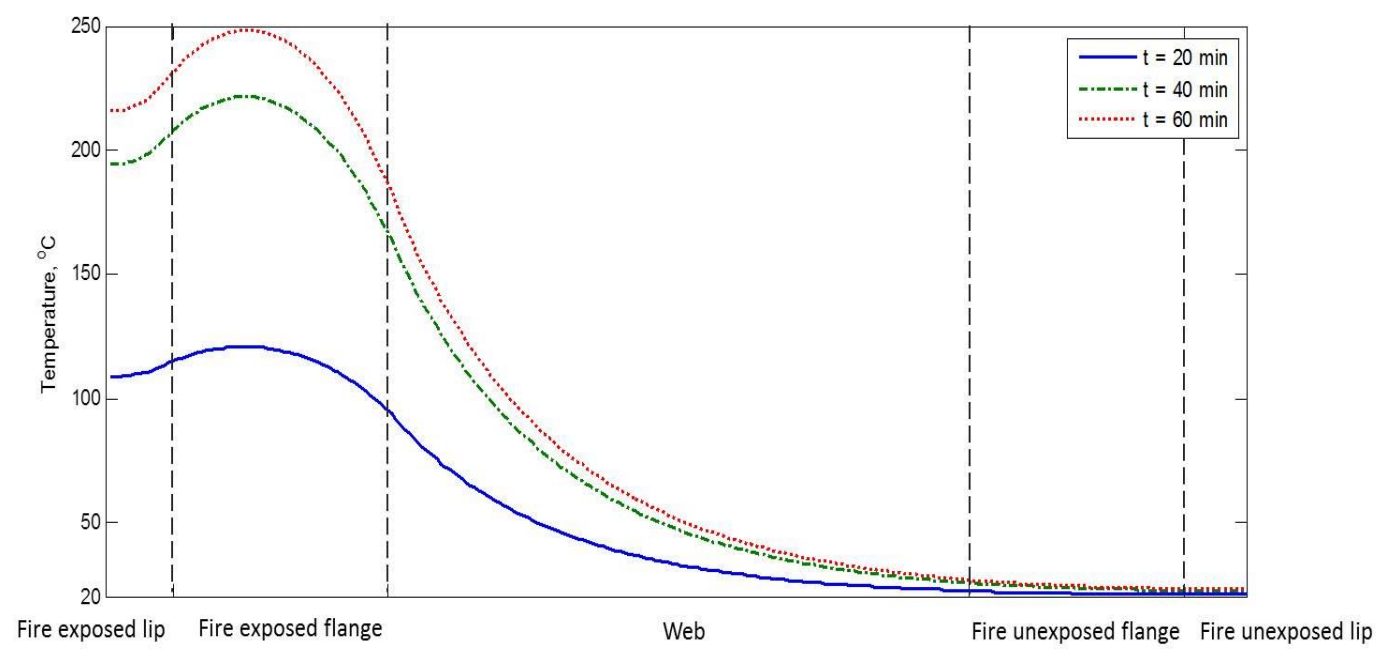

(a)

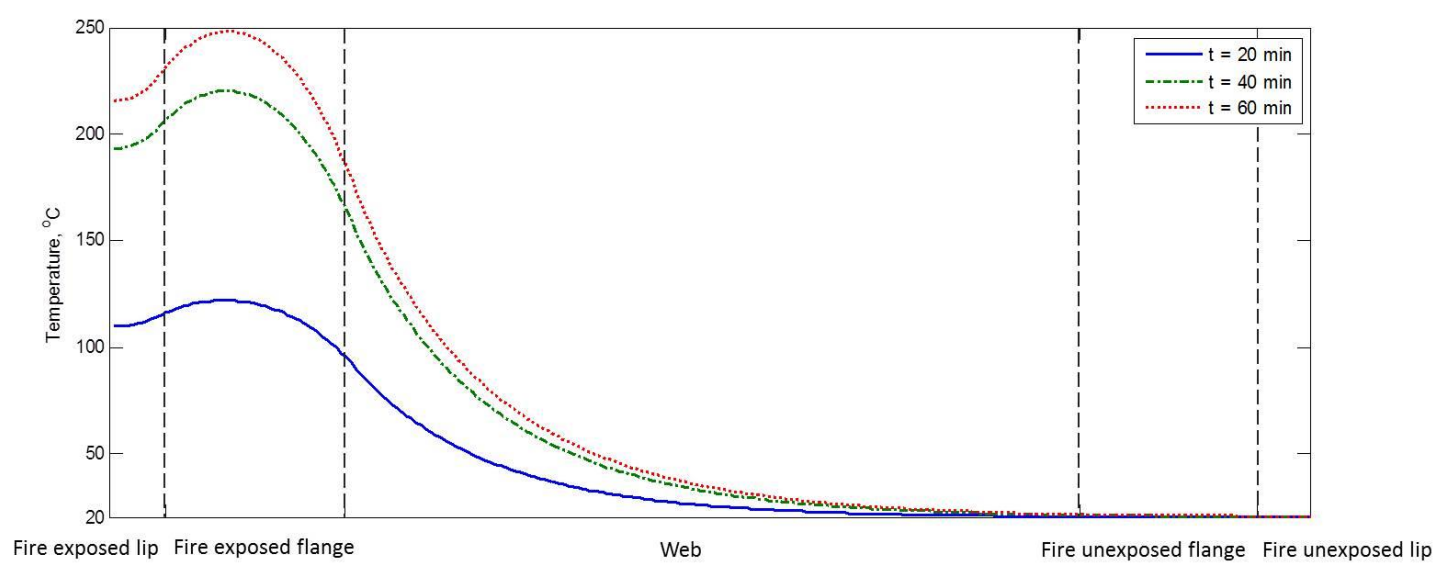

(b) 
Fig.2 Temperature distributions on channel-section when its one side is exposed to elevated temperatures. (a) Section dimensions: $d=200 \mathrm{~mm}, b=75 \mathrm{~mm}, c=20 \mathrm{~mm}, t=2 \mathrm{~mm}$. (b) Section dimensions: $d=300 \mathrm{~mm}, b=75 \mathrm{~mm}, c=20 \mathrm{~mm}, t=2 \mathrm{~mm}$.

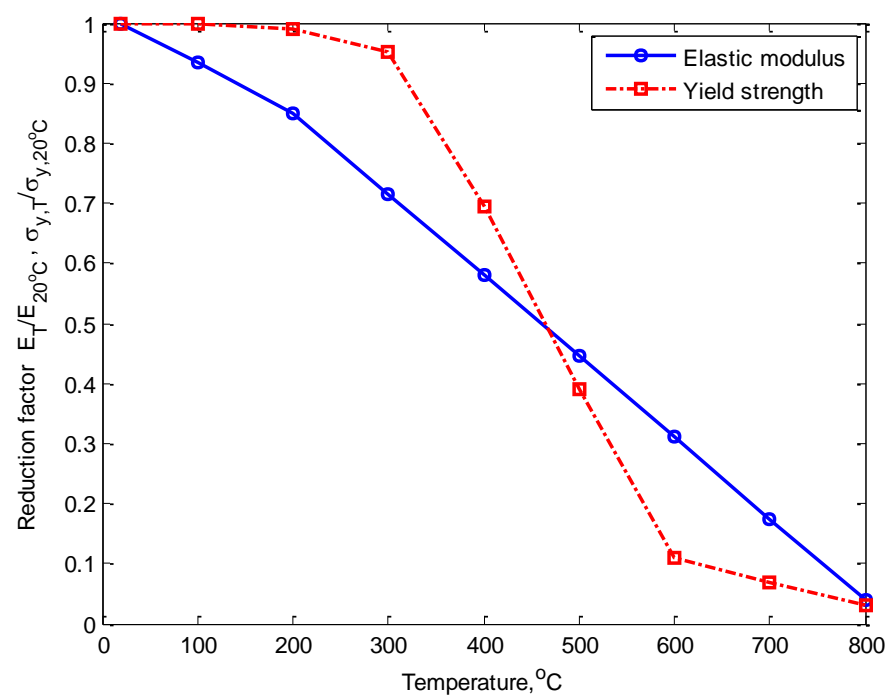

Fig.3 Reduction of mechanical properties of CFS at elevated temperatures (data from [7]). 


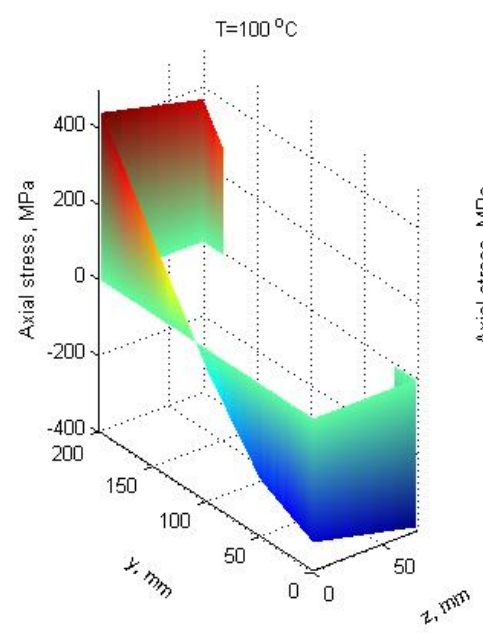

(a)

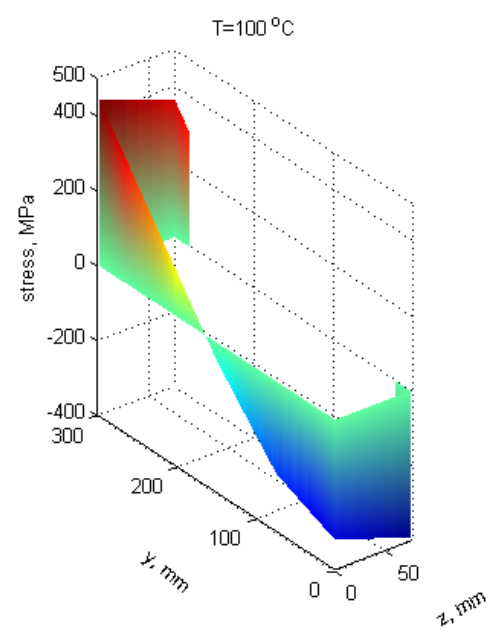

(d)

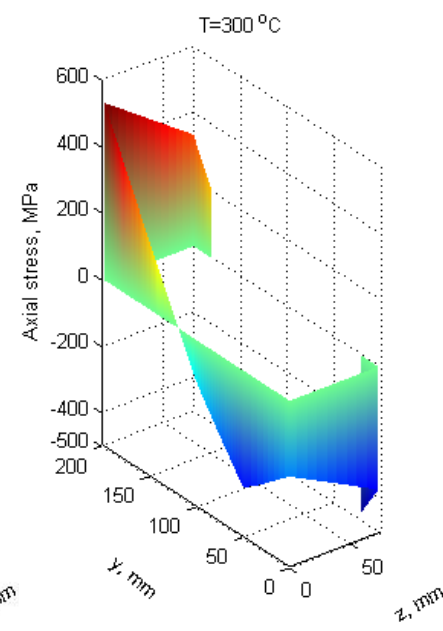

(b)

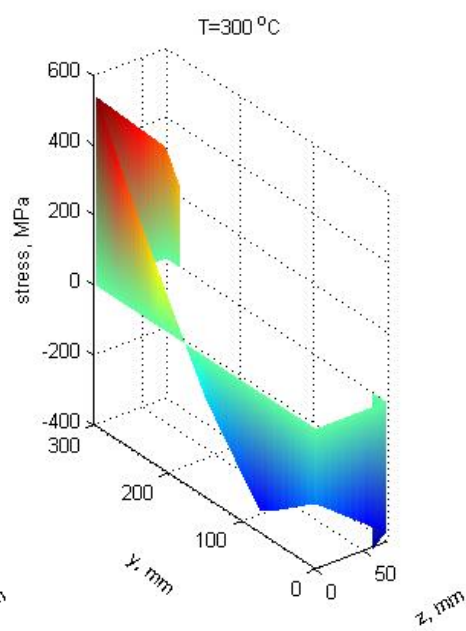

(e)

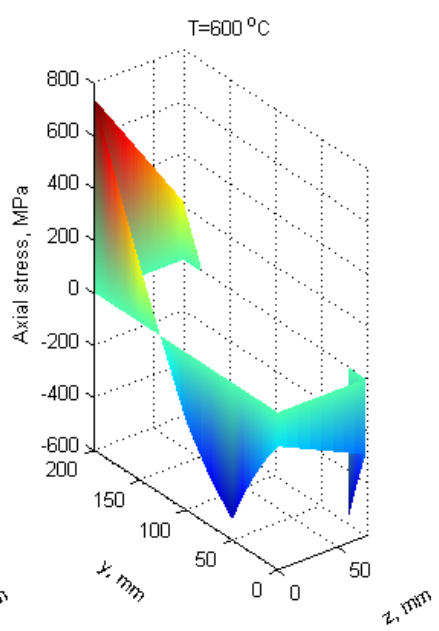

(c)

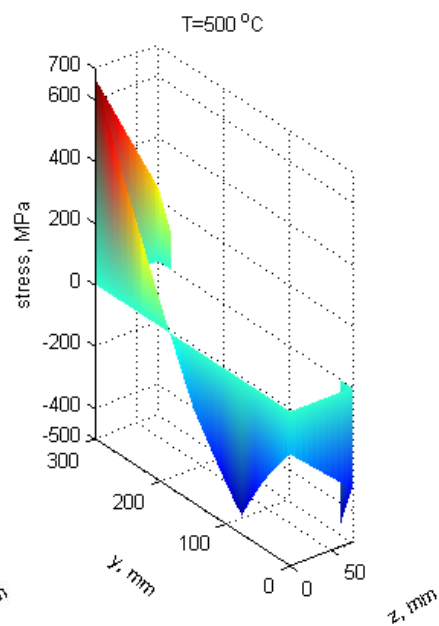

(f)

Figure 4. Pre-buckling stress distribution on middle section of a channel-section beam. (a)-(c) Section dimensions: $d=200 \mathrm{~mm}, b=75 \mathrm{~mm}, c=20 \mathrm{~mm}, t=2 \mathrm{~mm}$. (d)-(f) Section dimensions: $d=300 \mathrm{~mm}, b=75 \mathrm{~mm}, c=20 \mathrm{~mm}, t=2 \mathrm{~mm}$. 


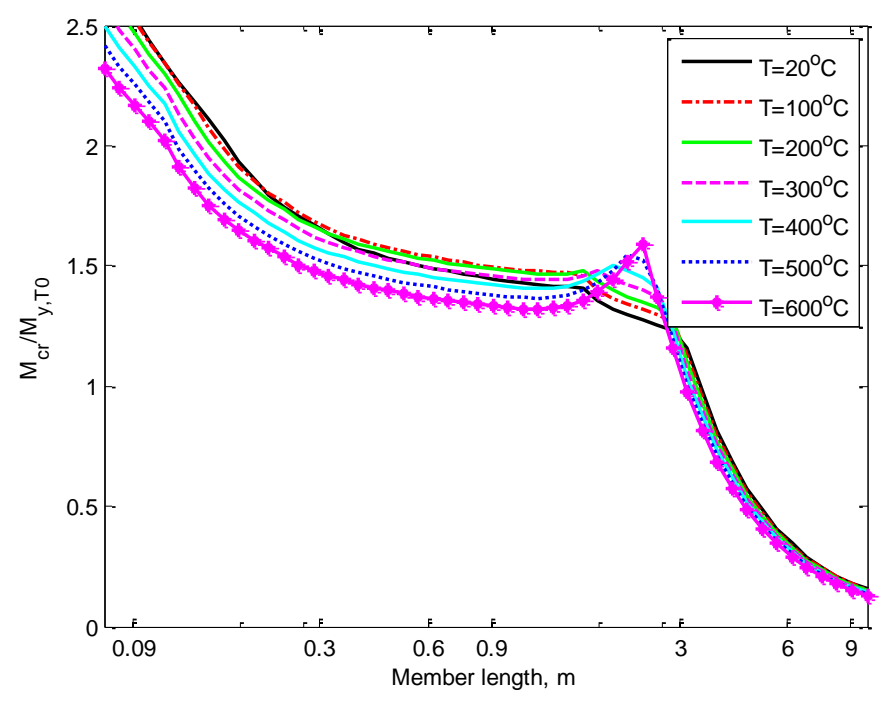

(a)

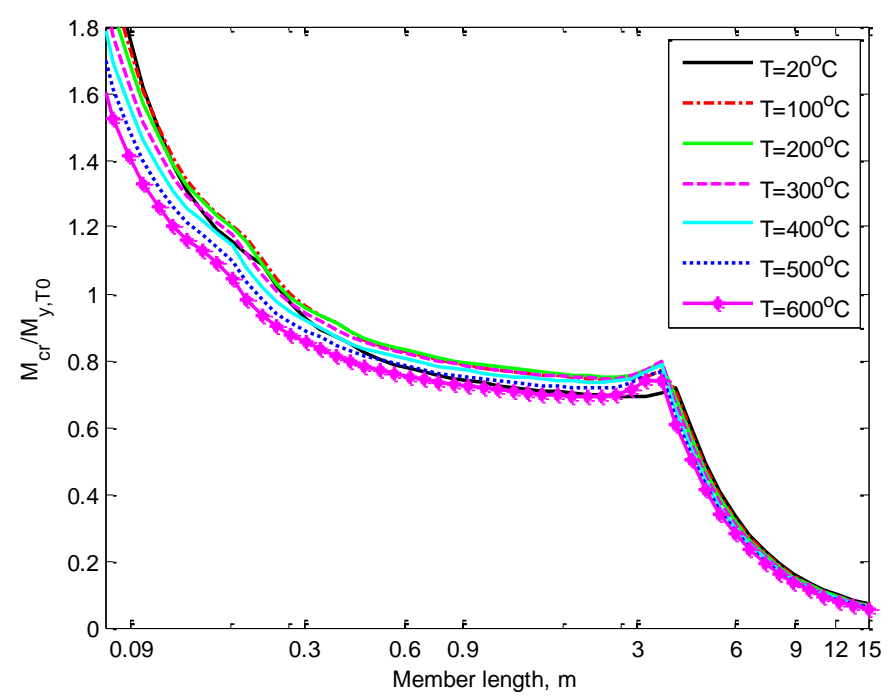

(b)

Figure 5. Critical moment $\left(M_{c r} / M_{y o}\right)$ of a channel-section beam subjected to uniformly distributed transverse loading at various elevated temperatures. (a) Section dimensions: $d=$ $200 \mathrm{~mm}, b=75 \mathrm{~mm}, c=20 \mathrm{~mm}, t=2 \mathrm{~mm}$. (b) Section dimensions: $d=300 \mathrm{~mm}, b=75 \mathrm{~mm}$, $c=20 \mathrm{~mm}, t=2 \mathrm{~mm}$. 


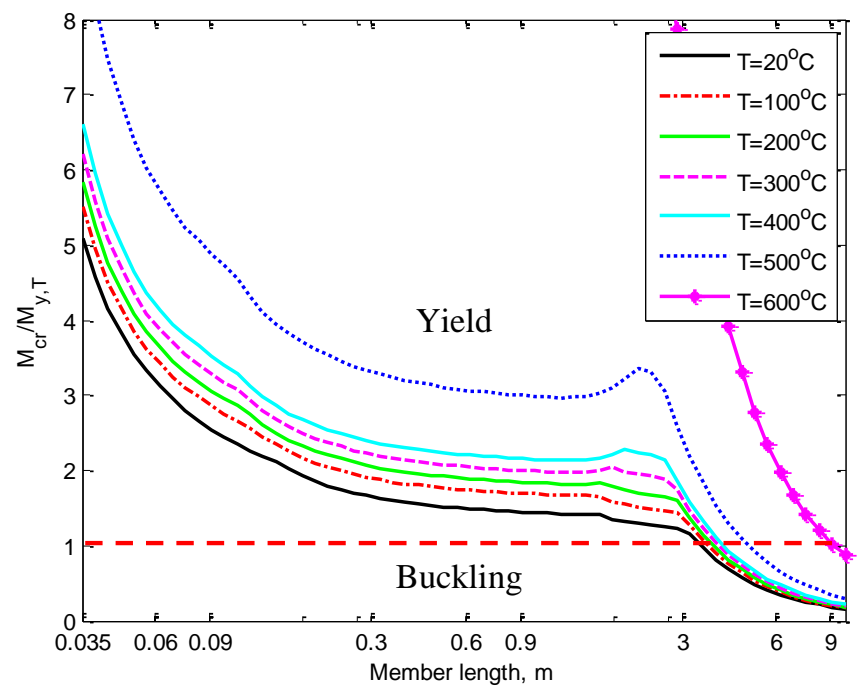

(a)

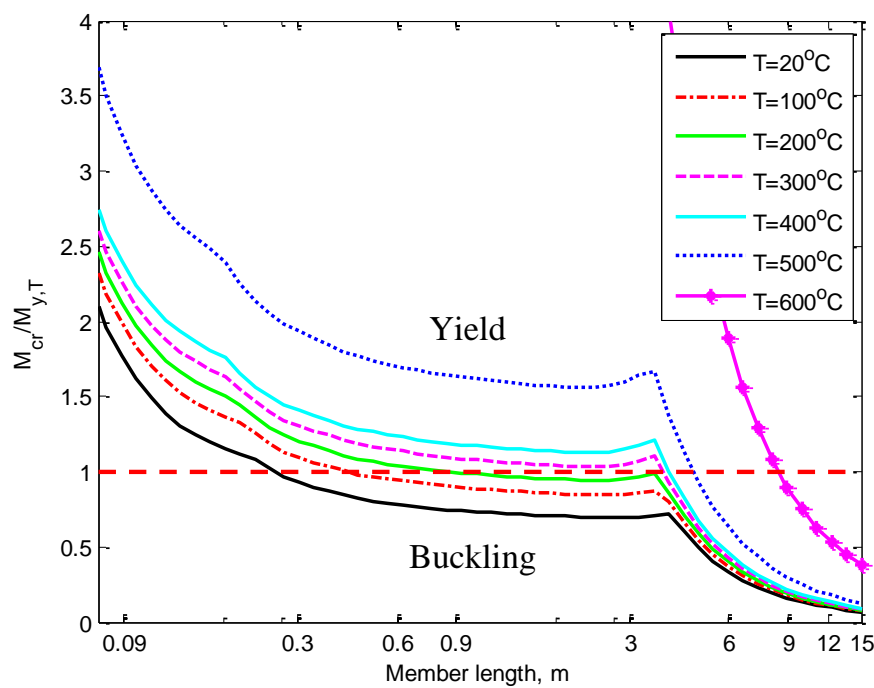

(b)

Figure 6. Relative critical moment $\left(M_{c r} / M_{y, T}\right)$ of a channel-section beam subjected to uniformly distributed transverse loading at various elevated temperatures. (a) Section dimensions: $d=200 \mathrm{~mm}, b=75 \mathrm{~mm}, c=20 \mathrm{~mm}, t=2 \mathrm{~mm}$. (b) Section dimensions: $d=300$ $\mathrm{mm}, b=75 \mathrm{~mm}, c=20 \mathrm{~mm}, t=2 \mathrm{~mm}$. 


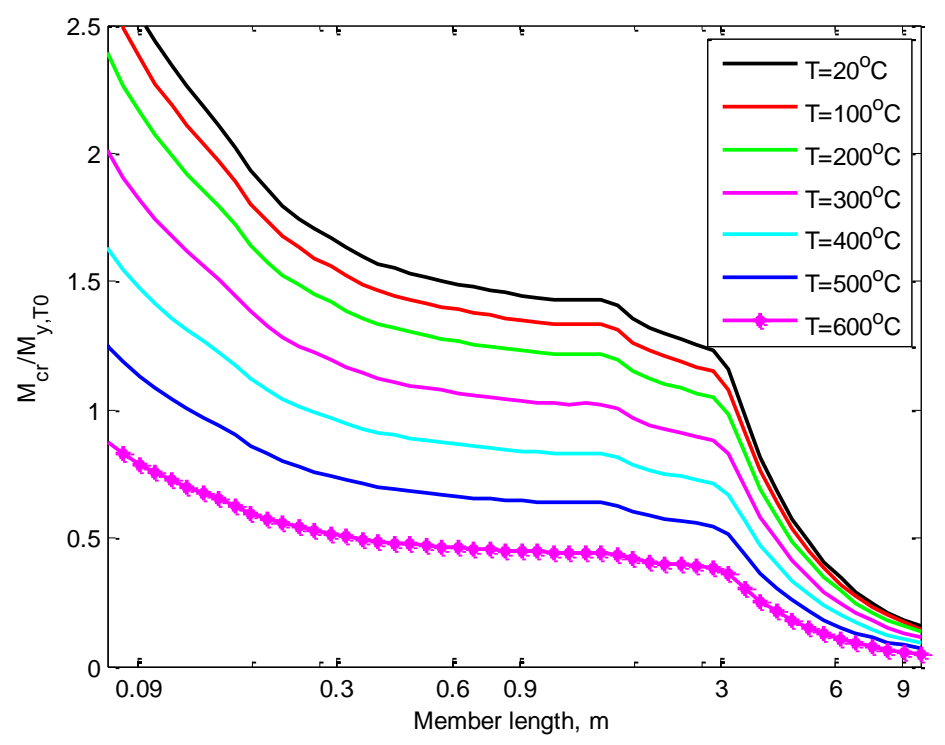

(a)

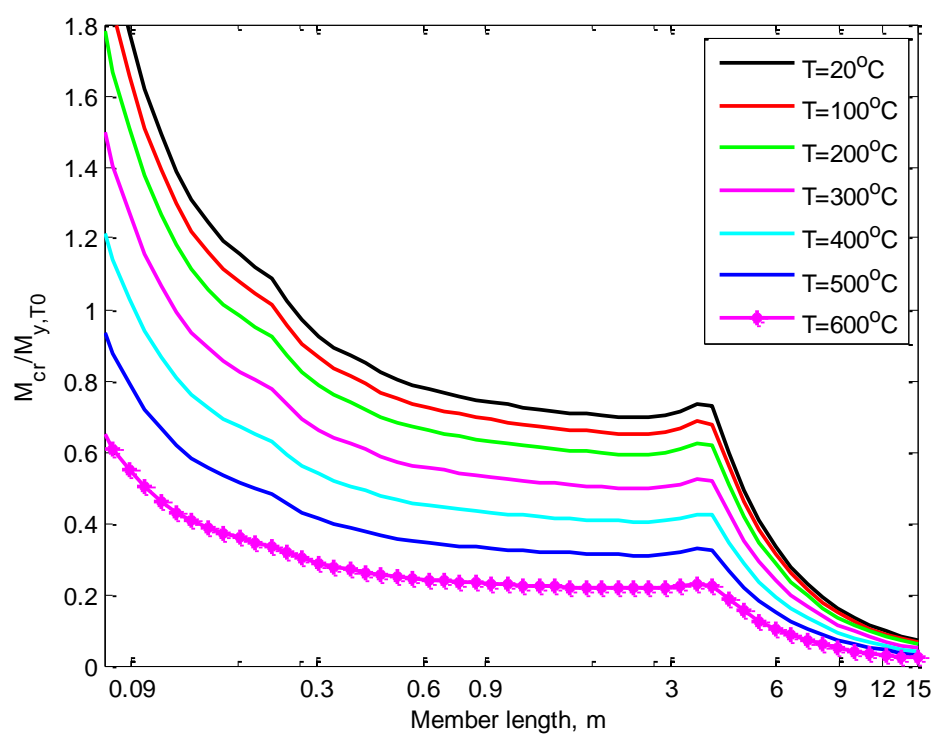

(b)

Figure 7. Critical moment $\left(M_{c r} / M_{y o}\right)$ of a channel-section beam subjected to uniformly distributed transverse loading at uniform elevated temperatures. (a) Section dimensions: $d=$ $200 \mathrm{~mm}, b=75 \mathrm{~mm}, c=20 \mathrm{~mm}, t=2 \mathrm{~mm}$. (b) Section dimensions: $d=300 \mathrm{~mm}, b=75 \mathrm{~mm}$, $c=20 \mathrm{~mm}, t=2 \mathrm{~mm}$. 


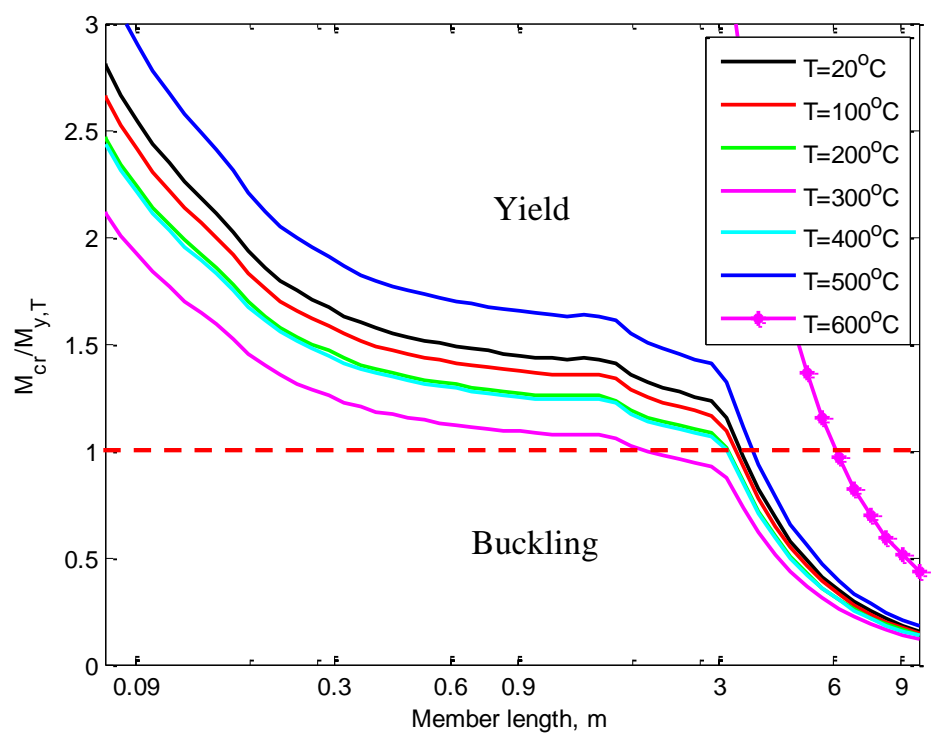

(a)

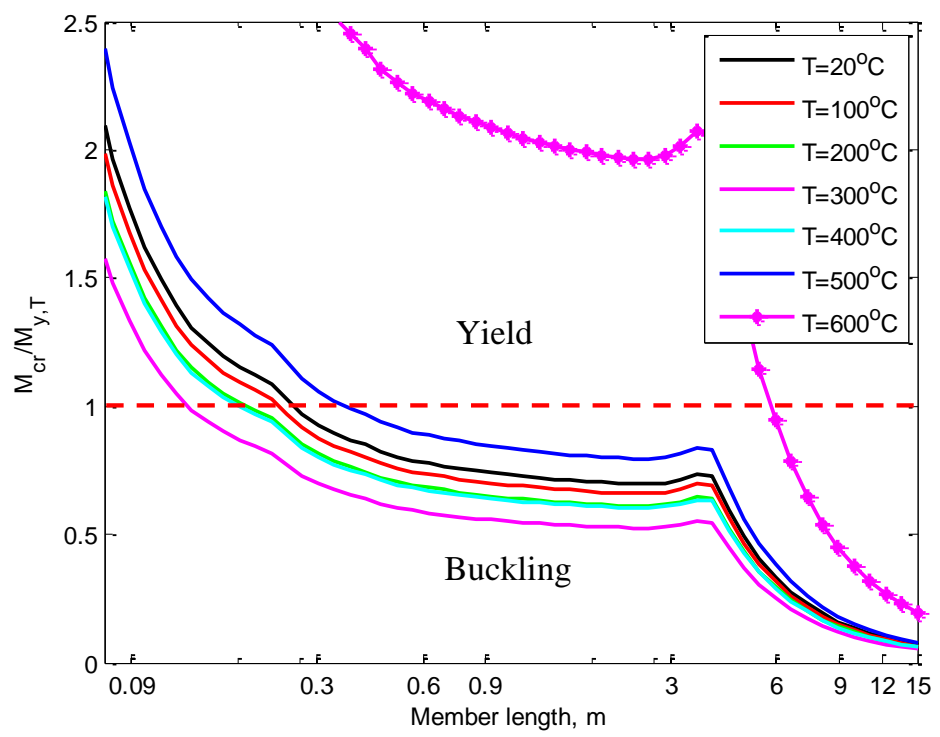

(b)

Figure 8. Relative critical moment $\left(M_{c r} / M_{y T}\right)$ of a channel-section beam subjected to uniformly distributed transverse loading at uniform elevated temperatures. (a) Section dimensions: $d=200 \mathrm{~mm}, b=75 \mathrm{~mm}, c=20 \mathrm{~mm}, t=2 \mathrm{~mm}$. (b) Section dimensions: $d=300$ $\mathrm{mm}, b=75 \mathrm{~mm}, c=20 \mathrm{~mm}, t=2 \mathrm{~mm}$. 